\title{
Gastrogeriatria: uma nova especialidade?
}

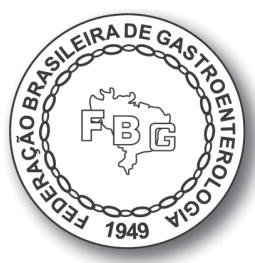

Eli Kahan Foigel

Luiz Henrique de Souza Fontes

Nas últimas décadas, as doenças crônicas não transmissíveis passaram a liderar as causas de óbito no país, ultrapassando as taxas de mortalidade por doenças infecciosas e parasitárias. Como decorrência da queda da mortalidade e da fecundidade no país, aumentou o número de idosos, particularmente o grupo com mais de 80 anos, havendo expectativa de que, nos próximos 20 anos, haja a duplicação da população idosa no Brasil, de 8 para $15 \%^{1}$ (Figura 1).

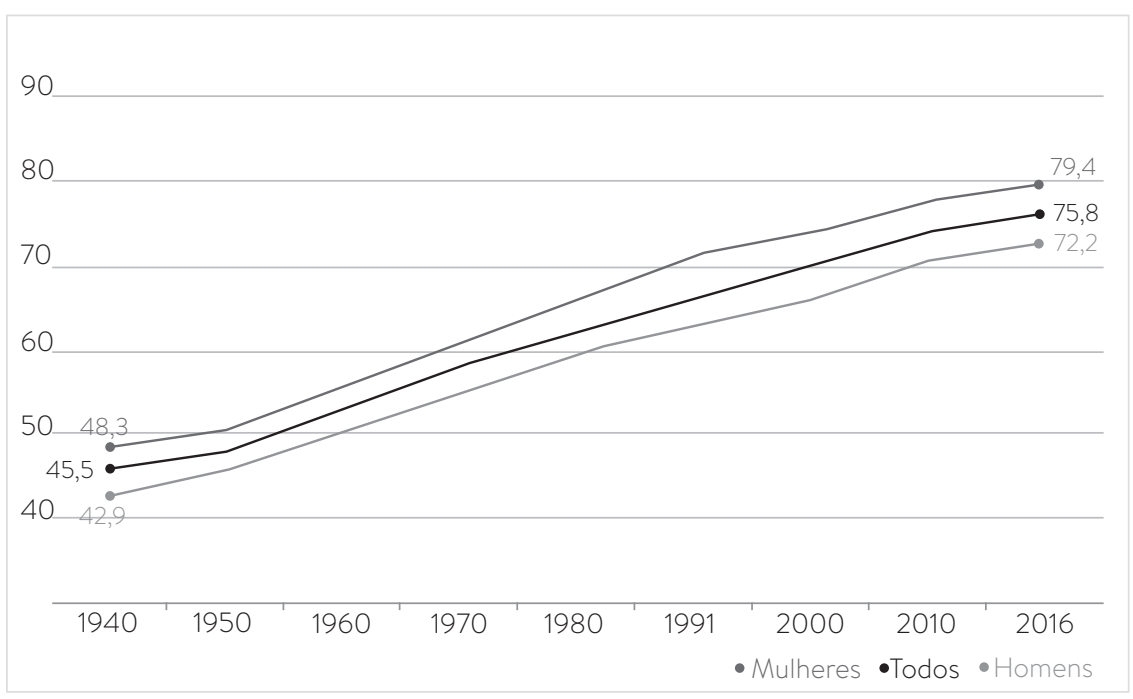

Figura 1 Expectativa de vida ao nascer - Brasil.

Fonte: IBGE. 
No Brasil e no mundo, a parcela da população com idade acima de 60 anos está crescendo em um ritmo mais acelerado do que qualquer outro grupo etário. Historicamente, o número de crianças sempre foi superior ao número de idosos. No entanto, espera-se que, em 2050, o percentual da população mundial acima de 60 anos ultrapasse o percentual de jovens de até 14 anos; essa transição deve ocorrer já em 2030.

O envelhecimento populacional pode ser explicado por dois fatores-chave o aumento da expectativa de vida e a queda da taxa de fecundidade ${ }^{2}$ (Figura 2). A expectativa de vida entre os sexos também vem aumentando, tendo uma diferença de mais de 7 anos para o feminino (Figura 3).

A primeira questão é definir quem é considerado idoso. No Brasil, como primeira referência pela Constituição Federal de 1988, que no seu artigo $230^{\circ}$ diz que "a família, a sociedade e o Estado tem que amparar as pessoas idosas" 3,4 , mas só se estabeleceu esse limite da idade pelo Estatuto do Idoso de 2003, que define que o idoso é a pessoa de idade igual ou superior a 60 anos $^{5}$. A Organi-

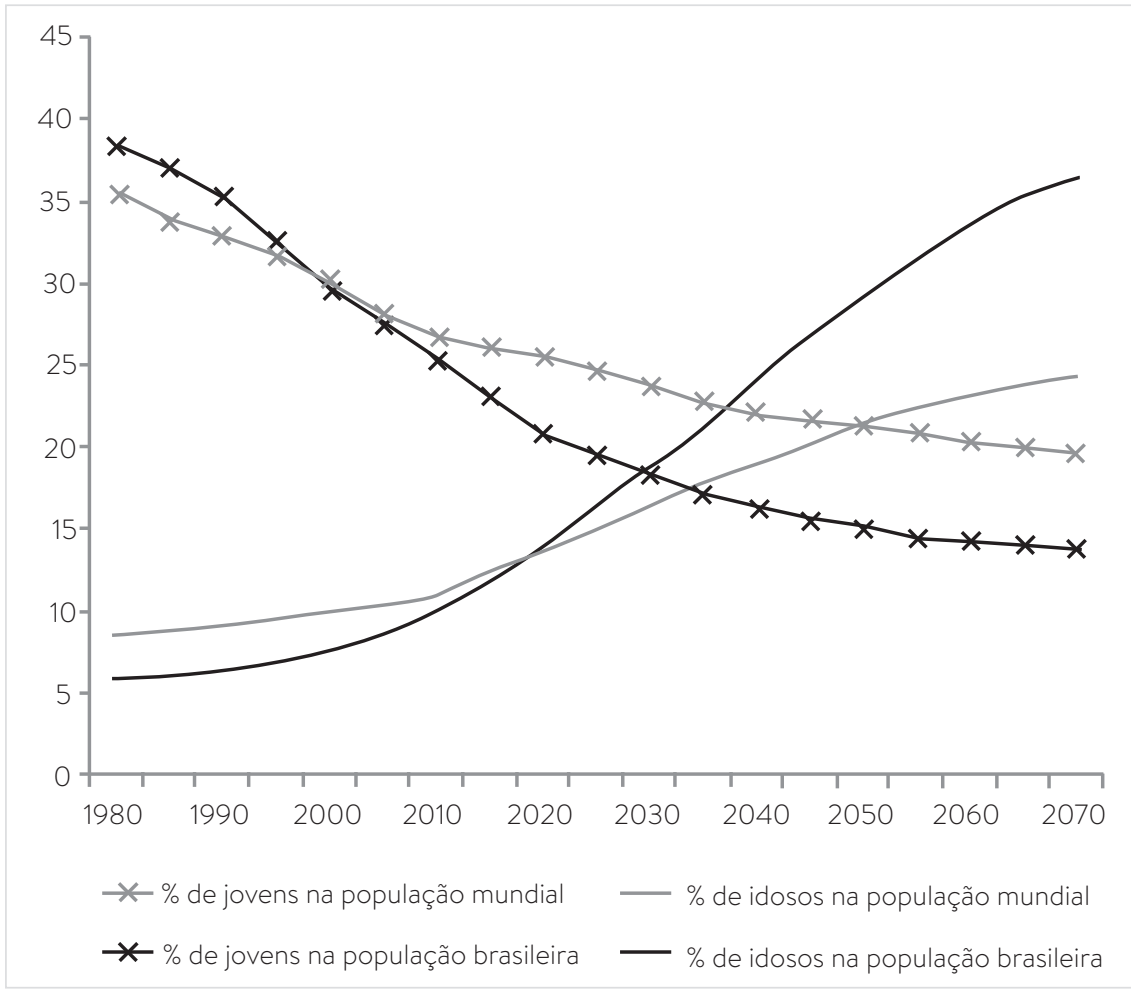

Figura 2 Envelhecimento populacional.

Fonte: IBGE. 
zação Mundial da Saúde (OMS), como no Brasil, também considera idoso o indivíduo com 60 anos ou mais ${ }^{6}$.

O envelhecimento é um processo normal, dinâmico e envolve perdas nos planos biológico, socioafetivo e político que refletem em expectativa de vida, morbidade, mortalidade prematura, incapacidade e má qualidade de vida. Existem modificações gerais na fisiologia da idade que acontecem em todos os sistemas e órgãos do corpo humano, como nos sistemas neurológico, cardiovascular, respiratório, renal e endócrino, que impactam no sistema digestório, cujos pontos principais são:

- Modificações de estrutura, função, metabolismo e fluxo sanguíneo no sistema nervoso central.

- Aumento de pressão arterial e diminuição do débito cardíaco.

- Redução da saturação da oxi-hemoglobina e diminuição da resposta à hipóxia.

- Redução da função renal.

- Diminuição da resposta e redução da secreção glandular6́.

Com o envelhecimento, os distúrbios gastrintestinais passaram a representar a $3^{\text {a }}$ causa mais comum das consultas na sociedade ocidental. Existem poucas mudanças dentro do trato gastrintestinal que inevitavelmente ocorrem como parte do envelhecimento. No entanto, com o aumento da idade, a incidência de doença gastrintestinal benigna (doença do refluxo gastresofágico, úlcera péptica, gastrite atrófica, diminuição da produção de secreção pancreática

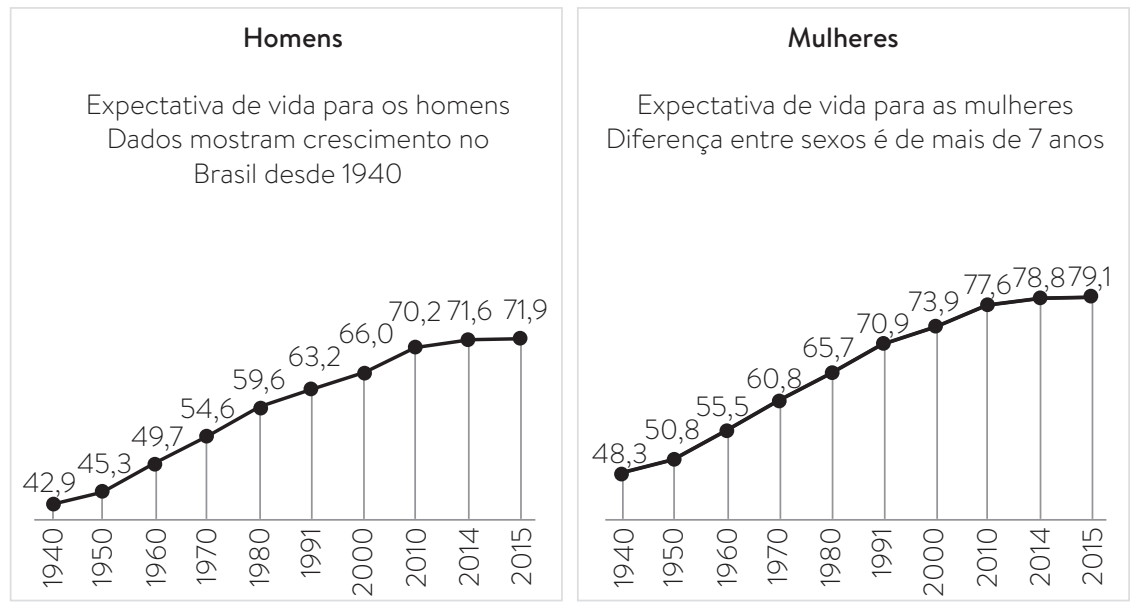

Figura 3 Expectativa de vida no Brasil.

Fonte: IBGE. 
e biliar, alteração da microbiota intestinal) e maligna aumenta (Figura 4). Embora os distúrbios gastrintestinais não apresentem características particulares em idosos, quando comparados a adultos mais jovens, eles podem apresentar sintomas mais graves por causa de comorbidades e polifarmácia ${ }^{7}$. O uso de várias medicações diariamente impacta no dia a dia dos pacientes e é difícil encontrar, entre os idosos, alguém que não tome nenhuma medicação que possa levar a boca seca, gastrite e obstipação, por exemplo ${ }^{8,9}$. As reações adversas aos anti-inflamatórios não hormonais (AINH) são mais comuns em pessoas com mais de 65 anos e são uma das principais causas de hospitalização nessa faixa etária9.

A disfagia ( $16 \%$ nesta população) e a constipação também são mais comuns, assim como a doença diverticular. Como causa da disfagia, podem-se definir os seguintes fatores: problemas odontológicos (perdas dentárias ou próteses mal adaptadas, disfunção e artrose da articulação temporomadibular); xerostomia; presbiesôfago (desnervação senil do esôfago); patologias sistêmicas (diabetes, colagenoses, miopatias, entre outras); neuropatias (acidente vascular cerebral, doença de Parkinson); medicamentosa (nitratos e bloqueadores de canais de cálcio); e as causas orgânicas (tumores malignos e benignos, estenoses, hérnias volumosas). Existe ainda outra causa deste sintoma nesta faixa etária, que são tumorações de estruturas adjacentes (linfonodos, aneurisma de aorta, tumores das vias aéreas) que podem levar a compressão extrínseca do esôfago, chamada de disfagia lusória.

A doença inflamatória intestinal parece apresentar um segundo pico de início entre os 60 e os 80 anos de idade, e a isquemia intestinal mesentérica está amplamente confinada à população idosa ${ }^{8,9}$.

Como consequência, as morbidades gastrointestinais nos idosos representam um ônus cada vez mais relevante para os sistemas públicos de saúde. Assim, é importante obter uma melhor compreensão das doenças mais frequentes em pessoas que vivem até a velhice avançada.

Dados da Organização das Nações Unidas (ONU) revelaram que indivíduos com mais de 65 anos têm 11 vezes mais probabilidade de desenvolver

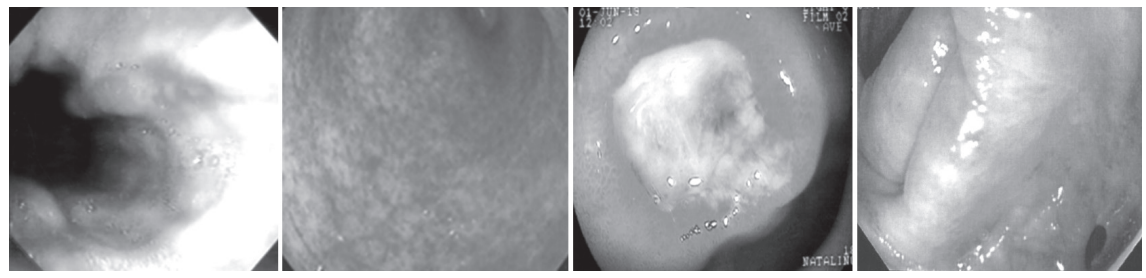

Figura 4 Esofagite de refluxo, gastrite atrófica, úlcera gástrica e divertículo de cólon. Fonte: Arquivo pessoal do autor. 
câncer que o jovem. Os tumores de pele, próstata, mama, cólon e reto, estômago, esôfago, bexiga, pulmão, linfoma e leucemia são considerados os mais comuns nos idosos. A incidência de casos de câncer do tubo digestivo tem números significantes em nosso país, sendo o de cólon e reto a $3^{\mathrm{a}}$ incidência nos homens e a $2^{\text {a }}$ nas mulheres, tendo ainda os cânceres de estômago e esôfago com incidência significante. Com o aumento da idade das pessoas, é necessária uma política de prevenção (Tabela 1).

Tabela 1 Distribuição proporcional dos 10 tipos de câncer mais incidentes estimados para 2018 por sexo, exceto pele não melanoma*

\begin{tabular}{|c|c|c|c|c|c|}
\hline \multicolumn{3}{|l|}{ Mulheres } & \multicolumn{3}{|l|}{ Homens } \\
\hline Localização primária & Casos & $\%$ & Localização primária & Casos & $\%$ \\
\hline Mama & 59.700 & $29,5 \%$ & Próstata & 68.220 & $31,7 \%$ \\
\hline Cólon e reto & 18.980 & $9,4 \%$ & $\begin{array}{l}\text { Traqueia, brônquios e } \\
\text { pulmão }\end{array}$ & 18.740 & $8,7 \%$ \\
\hline Colo do útero & 16.370 & $8,1 \%$ & Cólon e reto & 17.380 & $8,1 \%$ \\
\hline Traqueia, brônquio e pulmão & 12.530 & $6,2 \%$ & Estômago & 13.540 & $6,3 \%$ \\
\hline Glândula tireoide & 8.040 & $4 \%$ & Cavidade oral & 11.200 & $5,2 \%$ \\
\hline Estômago & 7.750 & $3,8 \%$ & Esôfago & 8.240 & $3,8 \%$ \\
\hline Corpo do útero & 6.600 & $3,3 \%$ & Bexiga & 6.690 & $3,1 \%$ \\
\hline Ovário & 6.150 & $3 \%$ & Laringe & 6.390 & $3 \%$ \\
\hline Sistema nervoso central & 5.510 & $2,7 \%$ & Leucemias & 5.940 & $2,8 \%$ \\
\hline Leucemias & 4.860 & $2,4 \%$ & Sistema nervoso central & 5.810 & $2,7 \%$ \\
\hline
\end{tabular}

* Números arredondados para múltiplos de 10.

Fonte: INCA, 2018.

A qualidade de vida no decorrer da idade é muito complexa, pois é necessário avaliar diversos domínios, principalmente os relacionados a problemas de saúde e aos efeitos dos tratamentos, que podem levar o idoso a experimentar déficits em diversos aspectos de sua vida. Por isso, é necessária a criação de uma nova especialidade denominada de Gastrogeriatria, criando uma interface entre a Gastroenterologia e a Geriatria, para estudar as peculiaridades das doenças do aparelho digestivo no idoso ${ }^{10}$.

\section{REFERÊNCIAS BIBLIOGRÁFICAS}

1. Brasil. Ministério da Saúde. A vigilância, o controle e a prevenção das doenças crônicas não-transmissíveis: DCNT no contexto do Sistema Único de Saúde brasileiro. Brasília: Organização Pan-Americana da Saúde; 2005.

2. Instituto Brasileiro de Geografia e Estatística (IBGE). 01/12/2017. 
3. Banco Nacional de Desenvolvimento Econômico e Social (BNDES). Envelhecimento e transição demográfica. Disponível em: www.bndes.org.br. Acessado em: 3/2/2017.

4. Brasil. Constituição Federal do Brasil de 1988. Art. 230.

5. Brasil. Lei n. 10.741/2003. Estatuto do Idoso.

6. Alvis BD, Hughes CG. Physiology considerations in the geriatric patient. Anesthesiol Clin. 2015;33(3):447-56.

7. Durazzo M, Campion D, Fagoonee S, Pellicano R. Gastrointestinal tract disorders in the elderly. Minerva Med. 2017;108(6):575-91.

8. Mathialagan R, Hariraj R. Gastroenterology in the elderly. Medicine Journal. 2015;43(6):352-5.

9. Gosney M, Tallis R. Prescription of contraindicated and interacting drugs in elderly patients admitted to hospital. Lancet. 1984;2(8402):564-7.

10. Toneti BF, Paula JM, Nicolussi AC, Sawada NO. Qualidade de vida relacionada à saúde de idosos com câncer em tratamento adjuvante. Rev Rene. 2014;15(6):1030-8. 